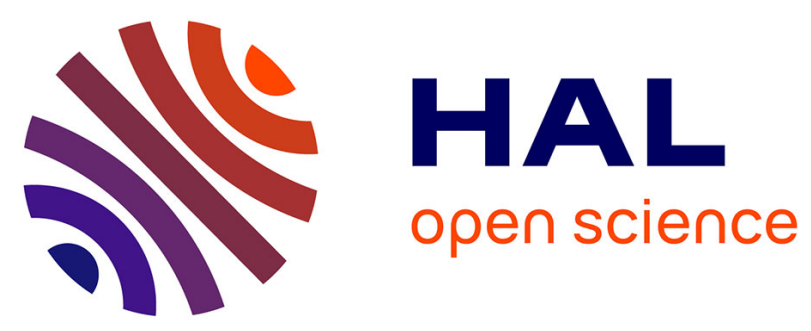

\title{
MODELING AND SIMULATION FOR AN OPTIMIZED DESIGN OF A DYNAMIC BENDING TEST
}

Rana Akiki, Fabrice Gatuingt, Cédric Giry, Nicolas Schmitt, Lavinia Stéfan

\section{To cite this version:}

Rana Akiki, Fabrice Gatuingt, Cédric Giry, Nicolas Schmitt, Lavinia Stéfan. MODELING AND SIMULATION FOR AN OPTIMIZED DESIGN OF A DYNAMIC BENDING TEST. 7th European Congress on Computational Methods in Applied Sciences and Engineering, ECCOMAS Congress 2016, Jun 2016, Crete Island, Greece. pp.242-253, 10.7712/100016.1808.9862 hal-01498192

\section{HAL Id: hal-01498192 https://hal.science/hal-01498192}

Submitted on 29 Mar 2017

HAL is a multi-disciplinary open access archive for the deposit and dissemination of scientific research documents, whether they are published or not. The documents may come from teaching and research institutions in France or abroad, or from public or private research centers.
L'archive ouverte pluridisciplinaire HAL, est destinée au dépôt et à la diffusion de documents scientifiques de niveau recherche, publiés ou non, émanant des établissements d'enseignement et de recherche français ou étrangers, des laboratoires publics ou privés. 


\title{
MODELING AND SIMULATION FOR AN OPTIMIZED DESIGN OF A DYNAMIC BENDING TEST
}

\author{
Rana Akiki $^{1}$, Fabrice Gatuingt ${ }^{1}$, Cédric Giry $^{1}$, Nicolas Schmitt ${ }^{1,2}$ and Lavinia Stéfan ${ }^{3}$ \\ ${ }^{1}$ LMT-Cachan \\ ENS Cachan/CNRS/Université Paris-Saclay \\ 61, avenue du Président Wilson, \\ 94235 Cachan Cedex, France \\ e-mail: \{akiki,gatuingt,giry\}@lmt.ens-cachan.fr \\ ${ }^{2}$ Université Paris Est Créteil \\ 61, avenue du Général de Gaulle \\ 94000 Créteil, France \\ e-mail: nicolas.schmitt@u-pec.fr \\ ${ }^{3}$ AREVA NC, DS, Technical Department \\ 1, Place Jean Millier \\ 92084 Paris la Défense, France \\ e-mail: lavinia.stefan@areva.com
}

Keywords: dynamic bending test, quasi-brittle material, experiment design, parametric study, material properties.

\begin{abstract}
Performance prediction of fibre-reinforced concrete structures under impact is of major importance in a wide range of industrial applications. Therefore, the study of the dynamic behaviour of the material is necessary to quantify the dynamic mechanical properties of the material in terms of both mechanical response and fracture behaviour : dynamic fracture energy and tensile strength. This study aims to design a modified Hopkinson bar bending test with a series of numerical simulations prior to the actual test in order to select a feasible experiment configuration. Results of a dynamic bending experiment on a steel fibre-reinforced concrete specimen loaded up to failure are presented.
\end{abstract}




\section{INTRODUCTION}

Performance prediction of fibre-reinforced concrete structures under impact is of major importance in a wide range of industrial applications. Therefore, the study of material dynamic behaviour is necessary to quantify its dynamic mechanical properties in terms of both the mechanical and fracture behaviours. Tested under high strain rates, cement-based materials tend to be strain-rate sensitive, which causes the mechanical behaviour to be significantly different from what is observed under quasistatic conditions $[1,2]$. To cite a few, tensile strength and fracture energy are both loading rate-dependent material properties.

Investigations of the behaviour of materials under high loading rates have resulted in new experimental techniques. The Hopkinson pressure bar was first introduced by Bertram Hopkinson as a way to measure the elastic wave propagation in a metal bar [3]. This technique was then refined by Kolsky [4] to measure stress and strain, by using two Hopkinson bars in series, and is now known as the split Hopkinson pressure bar (SHPB). The first tests investigated the dynamic compressive behaviour of materials.

Since then, many experiments have been performed for the characterization of the tensile strength over a wide range of strain rates, whereas only a few data are available for the fracture energy. The aim of this work is to provide a method for analyzing the Hopkinson bar bending test prior to the experimental procedure via numerical simulations. Such method allows us to examine the effects of many parameters (geometry and loading conditions) that experimentally, would be costly and time-consuming. First, different configurations for the dynamic bending test, including aspects such as loading methods, sample configurations and impactor speed are investigated. Second, based on the numerical simulations, the final configuration of the dynamic bending test is chosen. Using the Hopkison bars apparatus, the experiment is then conducted on a fibre-reinforced concrete specimen. Two high-speed cameras are used in order to capture the entire event from the onset of loading, through crack initiation and propagation. Full displacement fields are obtained with digital image correlation done on a number of relevant images. First results are presented and analyzed.

\section{DESCRIPTION OF THE EXPERIMENTAL METHOD}

\subsection{Definition of the test configuration}

The bending test has been employed in Hopkinson bar dynamic fracture testing in several configurations (Fig. 1). Loading methods are varied: with only one bar for a one-point bending test (one-bar/1PB) [5], or for a three-point bending test using one bar (one-bar/3PB) [6], two bars (two-bar/3PB) [7] or three bars (three-bar/3PB) [8, 9]. The three-bar/3PB loading configuration includes the impactor, the incident bar and two transmission bars which are the supports of the beam tested. The specimen is placed between the incident and transmission bars and the striker is propelled towards the incident bar. A stress wave travels then through the incident bar. Upon reaching the sample, due to the mismatch of mechanical impedances between the bar material and that of the specimen, part of the incident stress wave is reflected back into the incident bar, and the rest is transmitted through the sample to the transmission bars. The incident, reflected, and transmitted stress waves are then analyzed to deduce the sample's mechanical response by using one-dimensional wave propagation theory; considering that the bars 
are sufficiently long.

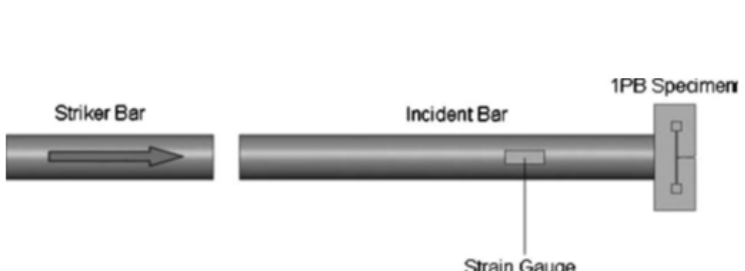

(a)

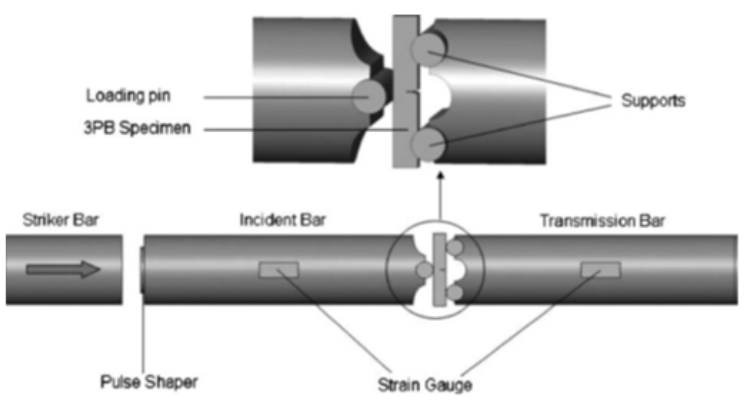

(c)

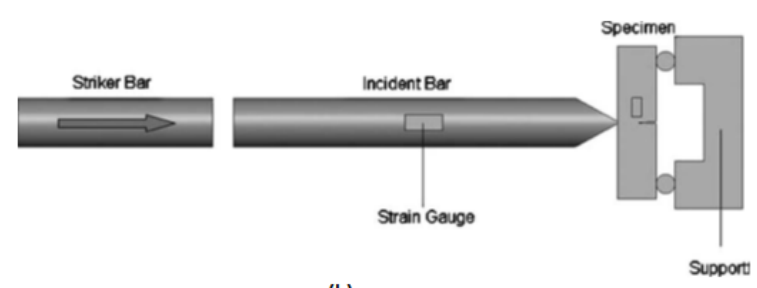

(b)

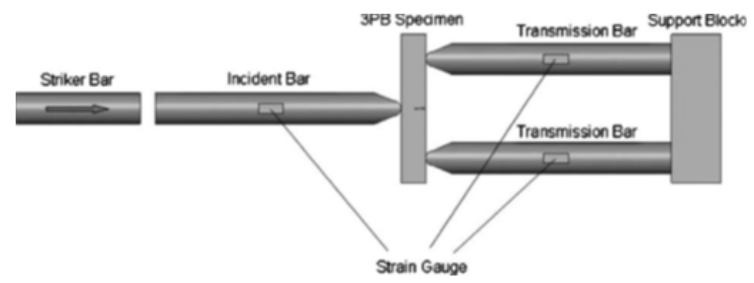

(d)

Figure 1: Different configurations of dynamic bending tests: (a) one-bar/1PB (b) one-bar/3PB (c) two-bar/3PB (d) three-bar/3PB [10].

\subsection{Data reduction}

Wave speed: The accurate measure of the wave speed in the bars is the first step in a valid data reduction for the Hopkinson bar experiment. This is done with a bar-to-bar test. By recording the time-of-arrival of both the incident and reflected waves at the incident bar strain gauge ( $t_{1}$ and $t_{2}$ respectively), and knowing the length between the strain gauge and the end of the $\operatorname{bar}\left(L_{I g}\right)$, the bar wave speed can be accurately calculated with equation 1 :

$$
c_{b}=\frac{2 L_{I g}}{t_{2}-t_{1}}
$$

The same is done between the signals measured from the incident gauge and the transmitted one, knowing the distance separating them. For the aluminium bars used in the lab's experimental apparatus, the mean value of the wave celerity is then computed: we find it to be equal to 5200 $\mathrm{m} / \mathrm{s}$.

Dispersion correction and time shifting: The waves during the test are measured using four strain gauges configured in a full Wheatstone bridge circuit. The strain gauges are used in pairs: the first pair is connected along the axis of the bar; one strain gauge is mounted axially and the other radially; the second pair of strain gauges is connected in the same manner but diametrically opposed. The electrical signals measured with the strain gauge bridges are converted to strain according to equation 2 :

$$
\varepsilon=\frac{V_{\text {out }}}{V_{\text {in }} \times f_{a} \times G F \times\left(1+\nu_{\text {alu }}\right)}
$$


where, $V_{\text {out }}$ is the electric potential measured, $V_{\text {in }}$ is the electric potential applied across the strain gauge, $f_{a}$ the amplification factor, $\nu_{a l u}$ the Poisson's ratio of the aluminium and $G F$ the gauge factor.

The time shifting of the waves consists of setting an origin matching the arrival of the incoming wave at the bar-specimen interface. Theoretically, it is estimated knowing the wave celerity and the distances between the gauges and the ends of the bars. Transport in space also requires taking into account the effect of dispersion, since waves with different lengths propagate in a medium at different speeds. This effect is observable in the Hopkinson bars, due to the threedimensionality of the bar. Taking into account the dispersion correction, the measured waves are transported to the input bar-specimen interface using the software DAVID [11].

Sample boundary velocity: A measure of interest not typically reported, but can be readily calculated, is the bar end velocity. The velocity of the incident bar end $v_{i}$ can be calculated using Equation 3:

$$
v_{i}=c_{b} \times\left(\varepsilon_{i}-\varepsilon_{r}\right)
$$

where, $\varepsilon_{i}$ and $\varepsilon_{r}$ are respectively the incident and reflected strain measures taken from the incident bar strain gauge and time shifted as exposed in the preceding paragraph.

Input force: The input force at the interface between the input bar end and the specimen $F_{i}$ can be calculated using Equation 4:

$$
F_{i}=E_{b} \times S_{b} \times\left(\varepsilon_{i}-\varepsilon_{r}\right)
$$

where, $E_{b}$ and $S_{b}$ are the Young's modulus and the section of the aluminium bar, respectively.

\section{MODELING OF THE HOPKINSON BAR EXPERIMENT}

\subsection{Numerical approach}

A three dimensionnel finite element model of the Split-Hopkinson Pressure Bar (SHPB) test of a pre-notched prismatic beam is developed. The dimensions (diameter and length) of the striker and the incident bar are fixed (Fig. 2). Different dimensions of the beam are studied: $40 \times 40 \times 160,60 \times 60 \times 240$ and $100 \times 100 \times 400$ (in millimeters). The numerical analysis is conducted using the explicit dynamic finite element code LS-DYNA [12].

Element type and mesh: Under-integrated eight-node solid hexahedron elements are selected for modeling the specimen and the bars. The specimen is described using fine mesh with finite elements having an aspect ratio of one in order to capture well the non-linear phenomena. The part of the experimental setting staying elastic are described using a coarser mesh with an aspect ratio larger than one. The summary of FE distribution in different portions of the FE model is given in table 1 and the finite element mesh in the specimen and the input bar end are shown in figure 3.

Material model: The selection of the appropriate material model is a critical step in the analysis since it determines the response of the structure to the type of loading it is subjected to. Experimental evidence $[1,2,13,14,15]$ indicates that the material, which will be studied in the 


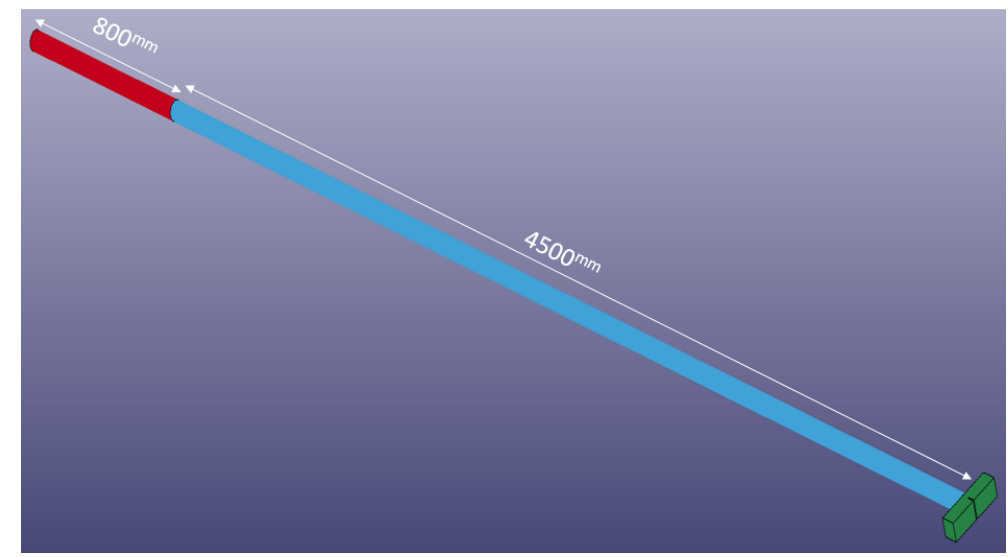

Figure 2: Model of the dynamic three-point bending test.

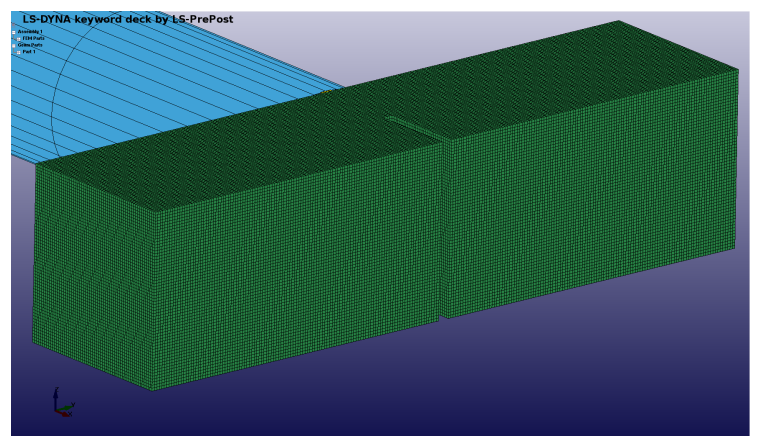

Figure 3: Mesh of the specimen and the input bar end.

\begin{tabular}{ccc}
\hline Entity & Nodes & Elements \\
\hline Striker & 4329 & 3680 \\
Input Bar & 22126 & 20700 \\
Specimen & 115816 & 107100 \\
\hline
\end{tabular}

Table 1: Mesh details of the components in the FE model.

future, is quasi-brittle and exhibits sensitivity to strain-rate. Therefore, an elasto-plastic damage model with rate effects, namely the continuous surface cap model (MAT-159) is chosen [16]. It takes into account strain softening, modulus reduction due to damage as well as rate effects. The striker and bar materials show a yield strength higher than the stress state expected during the test. Consequently, they are modeled as linear elastic materials.

Contact definition: The contact algorithm uses the penalty method, which allows penetration to occur but penalizes it by applying surface contact force models. Automatic surface to surface contact type category is used for the simulations, being adequate for the modified Hopkinson bar experiment which does not involve penetration of bodies.

Application of constraints: The axial direction of the striker and incident bar being along the X-direction of global cartesian coordinate system, the specimen displacement is constrained 
in this direction to achieve a three-point bending configuration. As for the one-point bending configuration, no constraints are applied, and the specimen is in a free-free condition.

\subsection{Results and discussion}

The response of the beam under different loadings (i.e., different initial striker velocities) are studied and three specimen sizes are considered. The global energies of the FEM are checked for negligeable hourglass energies. The numerical simulations of the three-point bending test show that damage initiates before an equilibrium state occurs (Fig. 4). Smaller spans have also been tested, but the equilibrium was nevertheless still not reached. The supports in the three-point bending test configuration do not come into play initially which puts the beam in a free-free condition. Thus, cracking occurs before supports are engaged. The specimen's deformation is caused by striker loading and material inertia only. Since the mechanical state

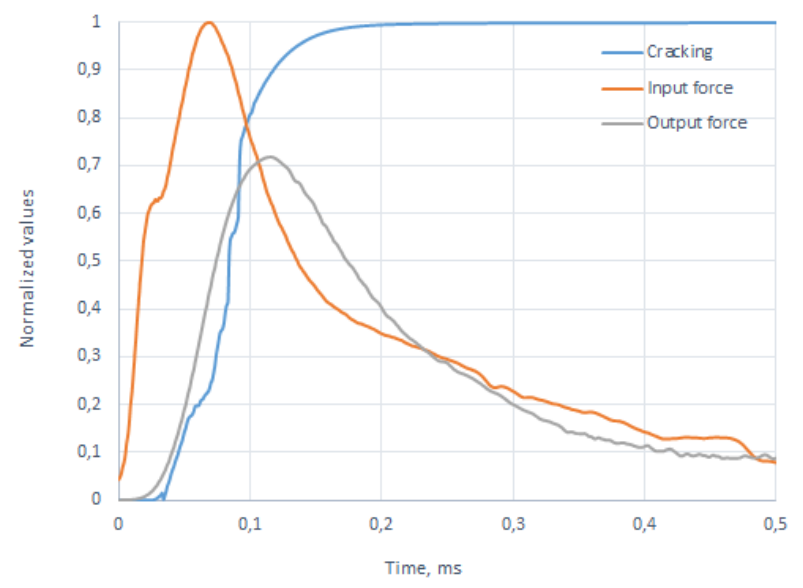

Figure 4: Input, output forces and cracking initiation with respect to time.

of the specimen is identical to the one of an unsupported beam, it is suitable to use a onepoint bending test configuration. The force-displacement evolutions at the load point of the beam are plotted in figure 5 for various dimensions of the specimen. One can observe that the experimental device needed (bearing for specimen) and the response are influenced by the size of the specimen. As a matter of fact, the specimen is practically held with no supports which makes it hard to be kept in place with increasing weights. Thus, the specimen has to be kept relatively small. Depending on the striker velocities, the specimen breaks more or less early. As shown in figure 6, with higher velocities, the input force is higher for a given displacement as well as the maximum displacement. Also, damage and therefore cracking of the specimen is reached earlier for higher initial velocities (Fig. 7). Finally, the configuration chosen for the test is the one-point bending with one input bar and no output bars. As for the initial velocity of the striker, the range reachable in the LMT facilities is sufficient to lead to the failure of the specimen, whatever its size may be. 


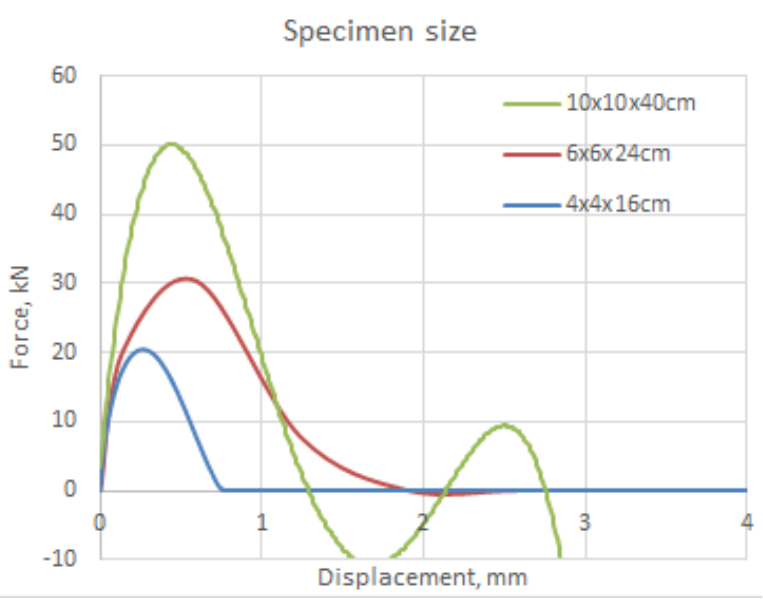

Figure 5: Force-displacement curves for different specimen sizes.

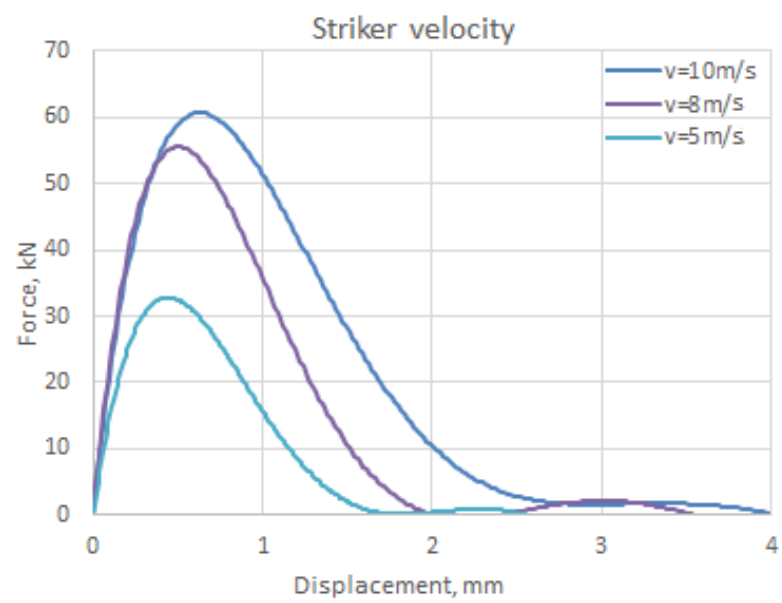

Figure 6: Effect on the striker velocity on the force-displacement curves.

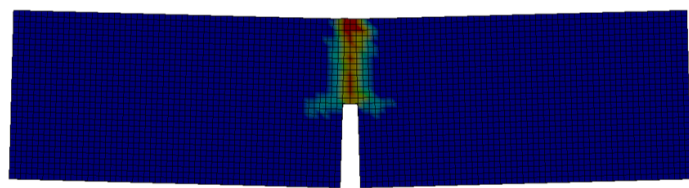

(a)

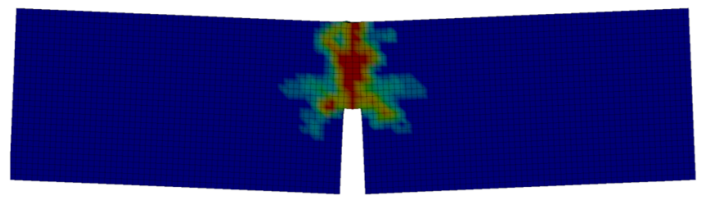

(b)

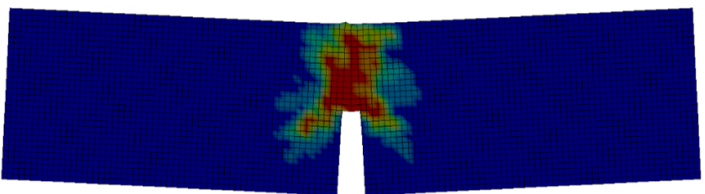

(c)

Figure 7: Damage in the specimen at $\mathrm{t}=1.4 \mathrm{~ms}$ for striker velocities of (a) $5 \mathrm{~m} / \mathrm{s}$ (b) $8 \mathrm{~m} / \mathrm{s}$ and (c) $10 \mathrm{~m} / \mathrm{s}$. 


\subsection{The experiment}

\subsubsection{Description of the apparatus and the measurement techniques}

The apparatus consists mainly of a gas gun, a striker, an incident bar, and a computercontrolled data acquisition system. The incident bar is $4.5 \mathrm{~m}$ long, while the projectile used is $0.8 \mathrm{~m}$ long. Both the bar and the projectile are made of aluminum alloy and have a common diameter of $60 \mathrm{~mm}$. The striker, input bar and specimen are positionned as mentionned in the previous section. The material tested in this work is a steel fibre-reinforced concrete with nominal specimen dimensions of $4 \times 4 \times 16 \mathrm{~cm}$ and a 2-cm deep pre-notch. Figure 8 shows the final experimental configuration adopted for the dynamic one-point bending test and the measurement techniques used.

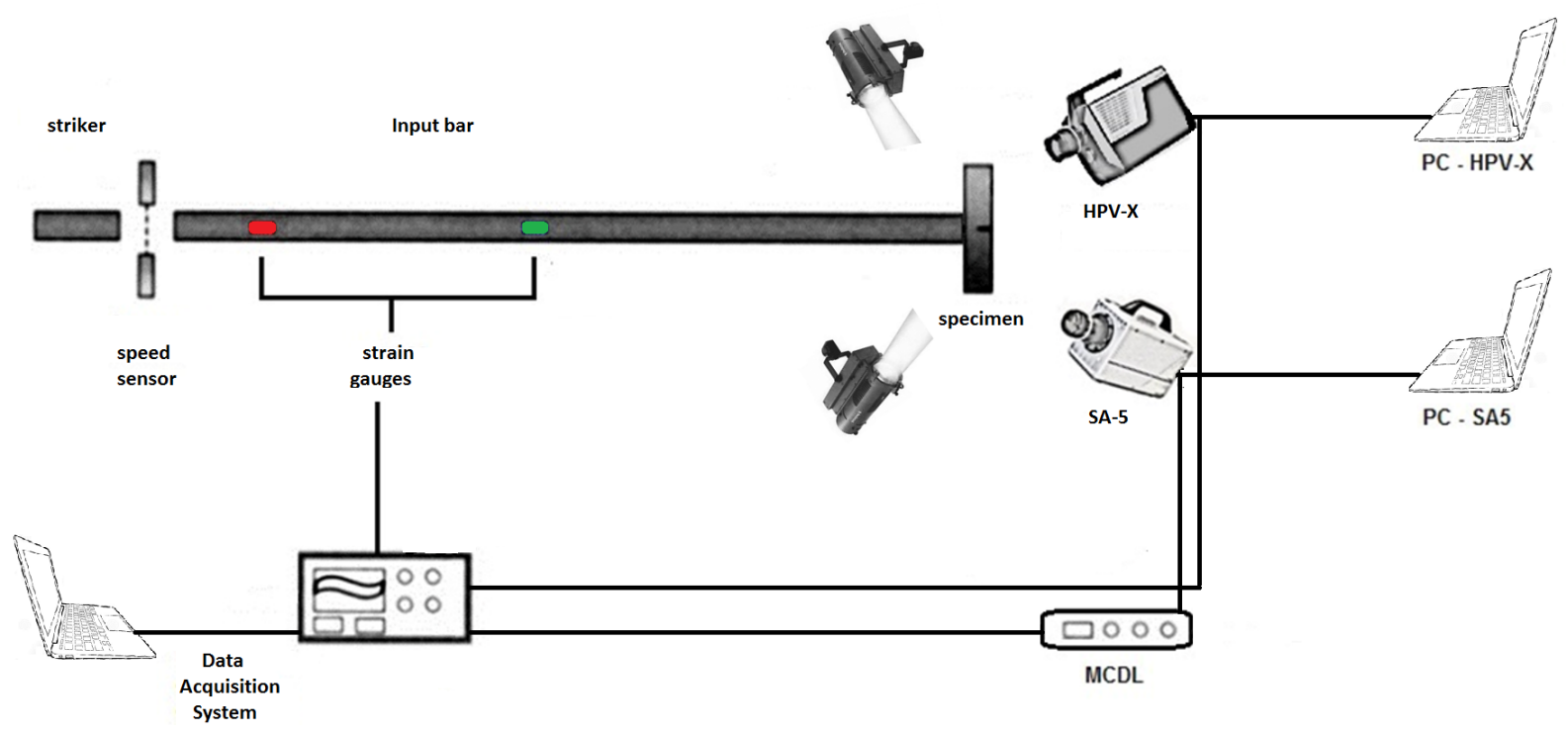

Figure 8: One-point bending test configuration.

Two strain gauge brigdes mounted at two locations on the incident bar provide strain measurements. The first one is used to trigger the camera's system and start recording, whereas the second one is used to determine the time histories of the stress and strain at the bar-specimen interface. Two high-speed cameras are used: the Photron Fastcam SA-5 and the Shimadzu HPV-X. The Photron Fastcam SA-5 camera is capable of recording images with a maximum resolution depending on the frame rate. It is used to capture the entire event from the onset of loading, up to crack initiation and propagation. To do it, the camera is run at a nominal frame rate of 50,000 frames per second resulting in a recording throughout the total time of the test with a resolution of $256 \times 472$ pixels. For the Shimadzu HPV-X, the maximum frequency can reach up to 10 million frames per second for a 50,000 pixels resolution with a memory capacity capable of recording up to 256 images in total. Thus, this camera has recorded images of the area near the crack tip in order to obtain precise information about the crack initiation and propagation throughout the duration of the loading. The camera is run at 200,000 frames per second resulting in a total recording of $1280 \mu$ s with a resolution of $250 \times 400$ pixels. The images are used to perform digital image correlation with the Correli Q4 code developed in 
the LMT Cachan [17]. The artificial random pattern, obtained by spraying black spots on the surface of the beam, and the positionning of high-speed cameras are taken into account in order to measure a reliable displacement field.

\subsubsection{Experimental results}

Photos taken from the Fastcam SA5 follow the evolution of the crack at different times as shown in figure 9. Time reference corresponds to the triggering of the camera (i.e., arrival time of the wave at the location of the first gauge placed on the input bar).

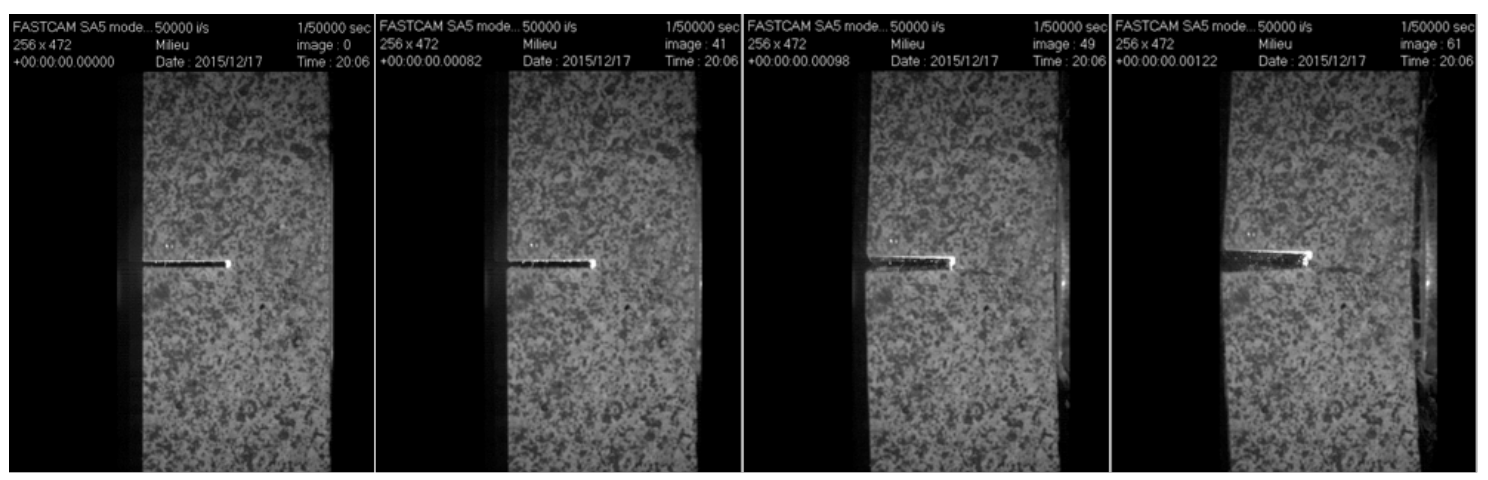

(a) $t=20 \mu s$

(b) $t=780 \mu \mathrm{s}$

(c) $t=940 \mu s$

(d) $t=1180 \mu \mathrm{s}$

Figure 9: High speed photographs of specimen subjected to impact loading.

The incident and reflected strain waves obtained experimentally are presented in figure 10 after being corrected for dispersion and time shifting. The velocity at the interface between the input bar and the specimen is calculated from the measured waves and is shown in figure 11 .

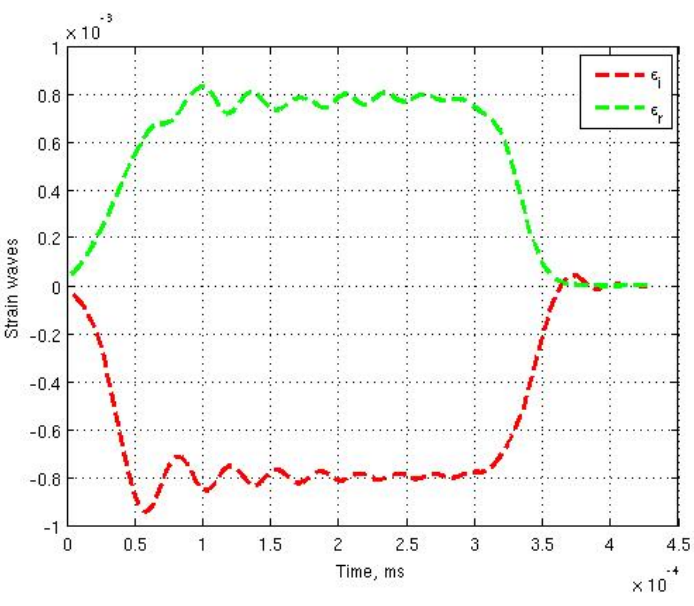

Figure 10: Incident $\left(\varepsilon_{i}\right)$ and reflected $\left(\varepsilon_{r}\right)$ strain waves after being shifted to the specimen's face.

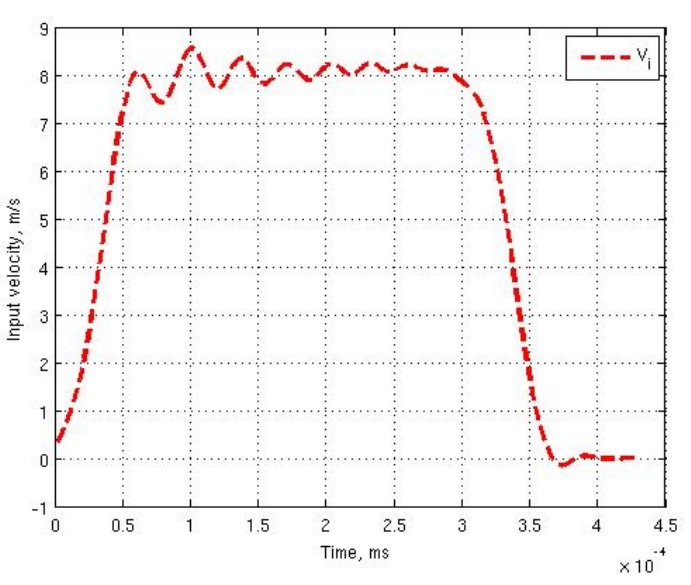

Figure 11: Velocity $\left(V_{i}\right)$ at the interface input barspecimen. 
The input force calculated at the interface between the input bar and the specimen is shown in figure 12.

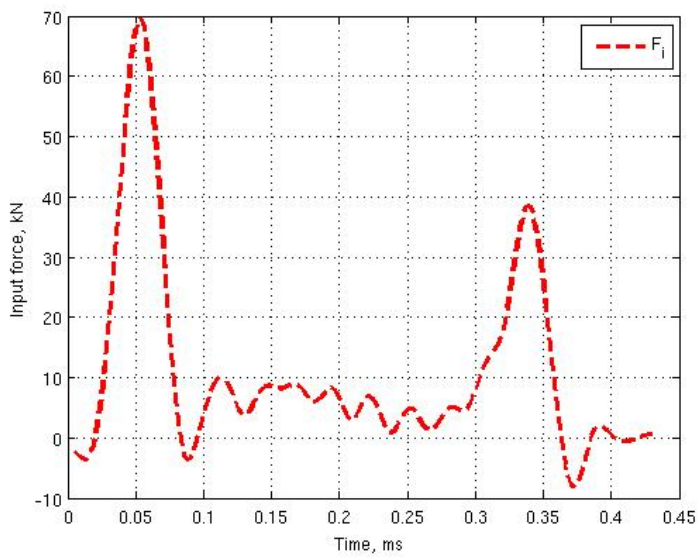

Figure 12: Evolution of input force $\left(F_{i}\right)$ in time.

The digital image correlation gives access to the strains and displacement fields as shown in figure 13. The initiation of the crack is easily detected even when it is not discernible to the naked eye (Fig.9b and Fig.13b). It can be quantified via the discontinuity of the Y-displacement (Fig.13b, c, d) by calculating the displacement jump and it is found to be equal to $0.32 \mathrm{~mm}$, $1.91 \mathrm{~mm}$ and $3.36 \mathrm{~mm}$ at the 3 respective times.

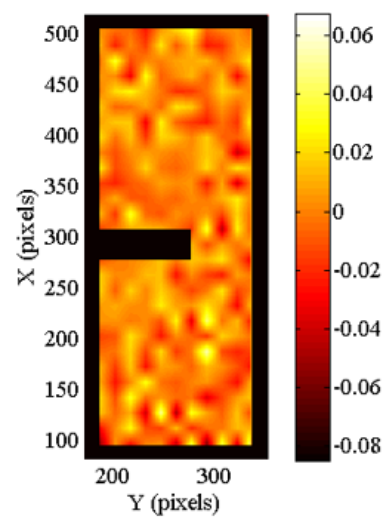

(a) $t=20 \mu s$

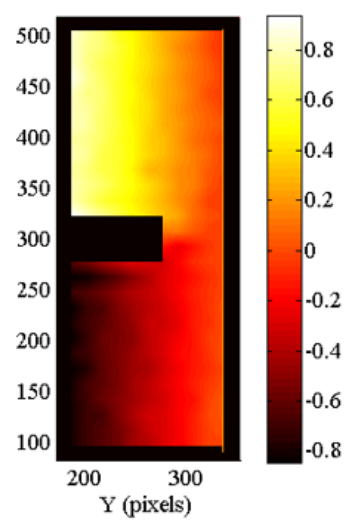

(b) $t=780 \mu \mathrm{s}$

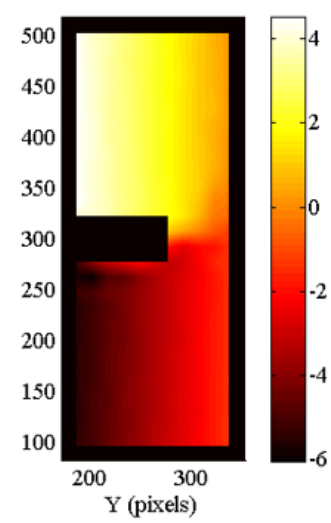

(c) $t=940 \mu s$

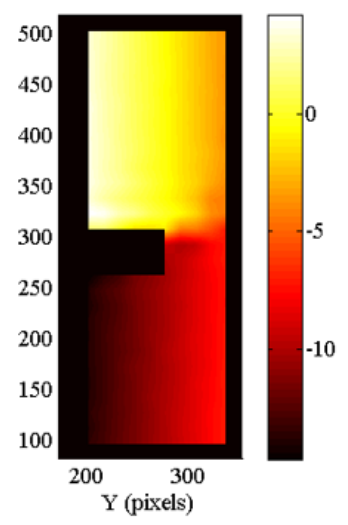

(d) $t=1180 \mu \mathrm{s}$

Figure 13: Displacement fields in the Y-direction measured with digital image correlation at different moments of the test.

\section{CONCLUSIONS}

This paper details the design of a dynamic bending test, through prior numerical analysis. The numerical simulations show that in the three-point bending test configuration, cracking occurs before the supports are engaged. Since the mechanical state of the specimen is identical to 
the one of an unsupported beam, the latter can be used for the analysis of quasi-brittle materials for which failure occurs at the onset of the test. After having chosen the suitable parameters for the test configuration, the experiment is performed. First results of a test in which a steel fibre-reinforced concrete specimen loaded up to failure are presented and show the cracking initiation and propagation. A future iteration of this experimental procedure might attempt to have a more localized force application. Additional work should also be put into an accurate computation of a fracture energy for the dynamic case where no equilibrium state is obtained.

\section{REFERENCES}

[1] T. S. Lok and P. J. Zhao, "Impact Response of Steel Fiber-Reinforced Concrete Using a Split Hopkinson Pressure Bar," Journal of Materials in Civil Engineering, vol. 16, no. 1, pp. 54-59, 2004.

[2] J. I. Daniel, V. S. Gopalaratnam, and M. A. Galinat, "State-of-the-Art Report on Fiber Reinforced Concrete," ACI Committe 544, vol. 96, no. Reapproved, 2002.

[3] B. Hopkinson, "A Method of Measuring the Pressure Produced in the Detonation of High Explosives or by the Impact of Bullets," Royal Society of London, vol. 86, pp. 437-456, 1914.

[4] H. Kolsky, "An Investigation of the Mechanical Properties of Materials at very High Rates of Loading,” Proc. Roy. Phys. Soc., pp. 676-700, 1949.

[5] G. Weisbrod and D. Rittel, "A Method for Dynamic Fracture Toughness Determination Using Short Beams," International Journal of Fracture, vol. 104, pp. 89-103, 2000.

[6] C. Bacon, J. Färm, and J.-L. Lataillade, "Dynamic Fracture Toughness Determined from Load-point Displacement,” Experimental Mechanics, pp. 217-223, 1993.

[7] F. Jiang, A. Rohatgi, K. Vecchio, and J. Cheney, "Analysis of the Dynamic Responses for a Pre-Cracked Three-Point Bend Specimen," International journal of Fracture, vol. 127, pp. 147-165, 2004.

[8] T. Yokoyama and K. Kishida, "A Novel Impact Three-Point Bend Test Method for Determining Dynamic Fracture-Initiation Toughness," Experimental Mechanics, vol. 29, no. 2, pp. 188-194, 1989.

[9] L. Rubio, J. Fernandez-Saez, and C. Navarro, "Determination of Dynamic Fractureinitiation in a Modified Hopkinson Pressure Bar," Experimental Mechanics, vol. 43, no. 4, pp. 379-386, 2003.

[10] F. Jiang and K. S. Vecchio, "Hopkinson Bar Loaded Fracture Experimental Technique: A Critical Review of Dynamic Fracture Toughness Tests," Applied Mechanics Reviews, vol. 62, no. 6, 2009.

[11] G. Gary, "DAVID - Instruction Manual," tech. rep., LMS, Ecole Polytechnique, Palaiseau (France), 2005. 
[12] LSTC, LS-DYNA Theory Manual. 2015.

[13] A. E. Naaman and V. S. Gopalaratnam, "Impact Properties of Steel Fibre Reinforced Concrete in Bending," The International Journal of Cement Composites and Lightweight Concrete, vol. 5, no. 4, pp. 225-233, 1983.

[14] N. Banthia, K. Chokri, Y. Ohama, and S. Mindess, "Fiber-reinforced Cement Based Composites Under Tensile Impact," Advanced Cement Based Materials, vol. 1, no. 3, pp. 131$141,1994$.

[15] S. Wang, M.-H. Zhang, and S. T. Quek, "Mechanical Behavior of Fiber-Reinforced HighStrength Concrete Subjected to High Strain-Rate Compressive Loading," Construction and Building Materials, vol. 31, pp. 1-11, 2012.

[16] Y. Wu, J. E. Crawford, and J. M. Magallanes, "Concrete Constitutive Models," in 12th International LS-DYNA Users conference, no. 1, pp. 1-14, 2012.

[17] G. Besnard, F. Hild, and S. Roux, "“Finite-element" displacement fields analysis from digital images: Application to Portevin-Le Châtelier bands," Experimental Mechanics, vol. 46, pp. 789-803, 2006. 